\title{
Deconstruction of Audiovisual Works and the Re-Construction of Its Translation
}

\author{
Peng $\mathrm{Yu}$ \\ School of Foreign Languages, Sichuan University of Science and Engineering 140\# Longshun Road, Yibin City, \\ Sichuan Province, China (644000). \\ Correspondence: Peng Yu, School of Foreign Languages, Sichuan University of Science and Engineering 140\# \\ Longshun Road, Yibin City, Sichuan Province, China (644000).
}

Received: June 25, 2018 Accepted: July 20, 2018 Online Published: August 24, 2018

doi:10.11114/ijecs.v4i1.3565 URL: https://doi.org/10.11114/ijecs.v4i1.3565

\begin{abstract}
With the gradual improvement of people's living standards, cultures are becoming more and more diverse, with a function to reconcile the contradiction between people's growing needs for a better life and their hard work and study. Among them, audiovisual (film and television) culture has a great impact on people's daily life, and people's demand for excellent audiovisual works, especially those from foreign cultures, is also increasing gradually. In this process, audiovisual translation has become a key link in the spread of exotic culture. Audiovisual translation is a special kind of translation, which is influenced by various elements. These elements mainly have four dimensions: sound, picture, text and culture. In order to study audiovisual translation well, it is necessary to deconstruct the film and television works, and then from the deconstructed elements, to find out their relations with the language translation. As an artistic cultural product, film and television works have three overt dimensions: picture, sound and text, and these three dimensions interact with each other to produce the fourth dimension, the covert dimension: culture. This paper mainly discusses the overt and covert dimensions of film and television translation, and conducts some case studies about their connection and influence on translation, so as to provide meaningful reference for scholars who are interested in such a field.
\end{abstract}

Keywords: translation; film and television; overt dimension; covert dimension

\section{The Deconstruction of Audiovisual Works}

In order to study audiovisual translation well, we should firstly deconstruct film and television works, that is, define its dimensions, find out its constituent elements and then discover the connection between translation and each dimension and element. With the elements of film and television works and their relations with translation, we can further explore the influence and limitation of each dimension and element in film and television translation.

Wikipedia defines film and television works in three layers: structure, content and culture. First of all, by the definition of its structure, a film, also called a movie, motion picture, theatrical film, or photoplay, is a series of still images which, when shown on a screen, creates the illusion of moving images due to the phi phenomenon. This optical illusion causes 
the audience to perceive continuous motion between separate objects viewed rapidly in succession.[1] From this, we can draw the conclusion that there are two essential elements in a film and television work: picture and sound. By definition of its content, some films have become popular worldwide attractions by using dubbing or subtitles to translate the dialog into the language of the viewer.[2] From this, we can draw the conclusion that the content of film and television works includes language and text. Usually this content is presented in the form of dialogue and subtitles. According to its cultural definition, films (film and television works) are cultural artifacts created by specific cultures. They reflect those cultures, and, in turn, affect them. Film is considered to be an important art form, a source of popular entertainment, and a powerful medium for educating—or indoctrinating — citizens. The visual basis of film gives it a universal power of communication. [3] From this we can come to the conclusion that: various elements of film and television works constitute a collection, and thus form a special form of cultural products.

Based on the discussion above, the film and television products are mainly composed of four dimensions, that is, as an artistic cultural product, film and television works have three overt dimensions: picture, sound and text, and these three dimensions interact with each other to produce the fourth dimension, the covert dimension: culture. Various dimensions of film and television products influence each other and then a unique audiovisual ecosystem is formed, which is shown in the diagram bellow.

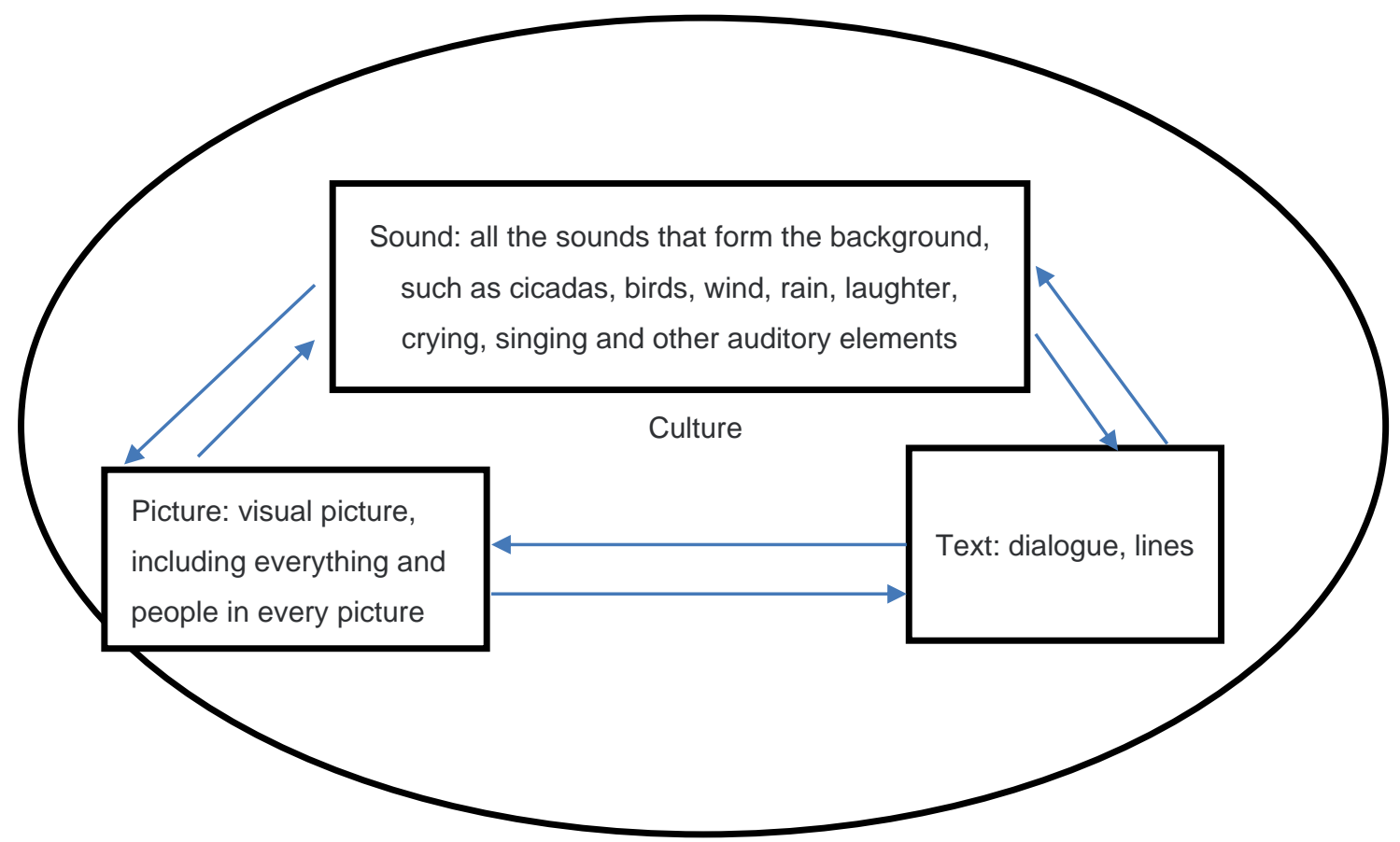

Figure 1. Various dimensions influence each other and form a unique audiovisual ecosystem

\section{The Re-Construction of Film and Television Translation}

Film and television translation is a special translation, which is a language conversion based on the complex audiovisual ecological system. In this system, the content presents two main characteristics, which are defined as "overt dimension" 
and "covert dimension" for the convenience of the study. The following part of this paper mainly discusses the overt and covert dimensions of film and television translation, and conducts some case studies about their connection and influence on translation.

\subsection{The Case Study of the Translation of "Overt Dimension"}

The "overt dimension" mainly comes from sound, picture and text, which are the basic contents of film and television works, and their characteristics are relatively stable. The translation of this dimension needs to consider the micro constraints, namely time, space, and the content of text and so on.

The theme song of the audiovisual work Frozen "Let It Go" (Original Motion Picture Soundtrack/Deluxe Edition, by Idina Menzel) has two Chinese versions: the official Chinese version "Sui Ta Ba (Let It Go)" by Beina Yao, and the folk version "Ru Shi Bing (Melting like ice)". The official Chinese version is good enough, but when searching the Internet for relevant information, the author found that the most popular version is not the official Chinese version "Sui Ta Ba (Let It Go)" by Beina Yao, but the folk version "Ru Shi Bing (Melting like ice)". Through a comparative analysis of the official version and the folk version, the author finds that the reasons why the folk version "Ru Shi Bing (Melting like ice)" has been praised by almost the whole Internet are as follows:

Firstly, its translation contains the meaning of the original. That is to say, in terms of time limit, the translation of this audiovisual work conveys the meaning of the original text in a concise and comprehensive way. We know that each frame of audiovisual work only stays for a few seconds, and if the translation is too long, the audience will spend a lot of energy to absorb the information in the translation, which will lead to a relatively poor viewing experience for them. Secondly, the translation takes into account the body language of the actor. That is, the matching degree between the content of the translation and the specific information of the picture (such as the body language of the characters, etc.) is fully considered in the translation of such a musical video. The translation of the folk version of "Melting like ice" takes the "mouth shape" of the actor into consideration, so that the translation is integrated with the pictures of the musical video, giving the audience an artistic viewing experience. On the other hand, excellent film and television works are works of art, and therefore, the Chinese version and its translation should also be elevated to the level of art before they can match the origin, the theme song "Let It Go" (by Idina Menzel). From this perspective, the translation of the folk version of "Melting like ice" is beautiful in rhythm, and the lyrics of the translation are in classical Chinese, which reflects that film and television translation is an art and a creative language art. This also tells us a truth that not only lofty officials and well-known translators can create the art of translation, the unknown people just like you and me can also become translation artists through efforts.

\subsection{The Case Study of the Translation of "Covert Dimension"}

The "covert dimension" is generated by the interaction of various overt dimensions, and the translation of this dimension needs to consider macro constraints, namely national tradition, ideology, national policy, etc. This is what the 
rest of this article will focus on. The following is case studies on the relationship and influence of overt and covert dimensions of film and television translation.

As a cultural medium, film and television product has become an important value carrier under globalization, and it is an important link and a key starting point for "Chinese culture's going abroad" which also creates a platform and opportunity for the international publicity of Chinese film and television products. "Chinese culture's going abroad" and the international publicity of film and television products complement each other and jointly contribute to the promotion of Chinese cultural soft power. Therefore, from the perspective of "Chinese culture's going abroad", it is of great practical significance and research value to summarize, from a micro point of view, the development status of international communication of Chinese audiovisual works and put forward countermeasures and suggestions for the overseas communication of Chinese film and television through the effort of analyzing the Chinese films and the analysis of the experience of "films' going abroad" of other countries.[4]

Moreover, what needs to be clear is that film and television translation must not be simply understood as the simple translation of the subtitle text in one language into another language, because it is also limited and affected by various elements.

a. Spring Festival Gala

Spring Festival Gala, short for "CCTV Spring Festival Gala Evening", is a comprehensive variety show held by the Central Radio and Television Station of China on the New Year's Eve every year to celebrate the Chinese New Year. Originated in 1979, it was designated as a national project in 2014.[5] The overseas publicity of Spring Festival Gala can let the Chinese people throughout the world feel the celebrating atmosphere of Spring Festival, which is beneficial for Chinese culture's going abroad, but at the same time, it will encounter some very challenging problems: for example, in the translation of audiovisual work "Yang Nian Spring Festival Gala" and "Xi Yangyang and Wolffy", the translator has to firstly consider such a question: how to deal with the translation of the Chinese character "Yang", because for the Chinese character "Yang", there are several different words in English that can express this Chinese meaning, and the referential meaning of these words is totally different. It is shown in the form below.

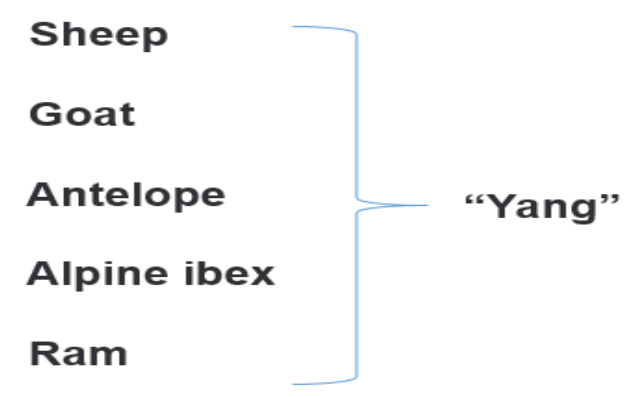


Searching the foreign Internet, the author found that foreigners are also very puzzled to translate the Chinese Year of "Yang", such as:

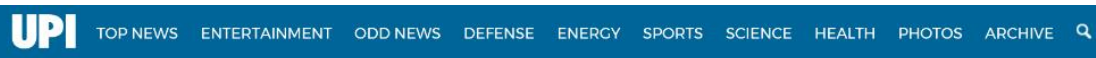

\section{Chinese New Year welcomes the Year of the 'Yang'}

Welcome to the year of the sheep, goat or ram. Specifically, the Year of the Yang.

By Andrew V. Pestano $\mid$ Feb. 19, 2015 at 11:41 AM Follow @upi

Q Comments $f$ Share $y$ Tweet $\triangle$ Email $B$ Pint
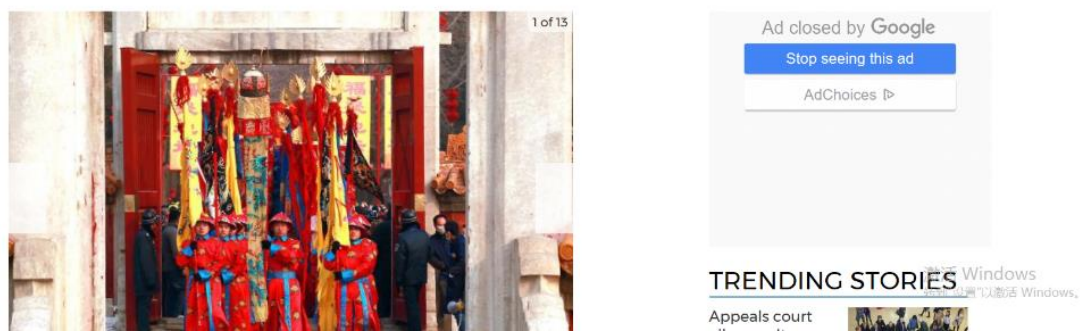

\begin{tabular}{|c|c|c|c|c|c|}
\hline 三 SECTIONS Q SEARCH & & & DAILYaNEWS & & LOG IN \\
\hline $\begin{array}{l}\text { Shocking video shows } \\
\text { Pennsylvania couple arguing } \\
\text { with neighbor before murd... }\end{array}$ & $e_{-2} e^{11}$ & $\begin{array}{l}\text { Wendy Williams' lifetime } \\
\text { biopic and documentary score } \\
\text { ratings gold }\end{array}$ & $\begin{array}{l}\text { 'I was shocked": Friend of } \\
\text { man found dead living out of } \\
\text { his car in the Bronx thought... }\end{array}$ & $\begin{array}{l}\text { 'I was so afraid of dying': Man } \\
\text { slasshed across face on } \\
\text { Manhattan-bound I train... }\end{array}$ & $\begin{array}{l}\text { Anna N } \\
\text { old dau } \\
\text { Birkhea }\end{array}$ \\
\hline
\end{tabular}

ADVERTISEMENT

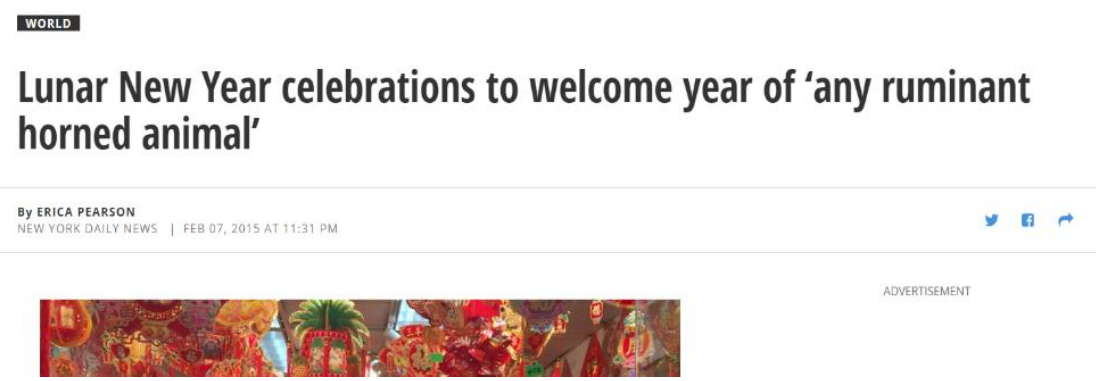

Then how we should deal with these problems in the translation of film and television is worth our thinking. Most importantly, in order to make the audiovisual works be accepted by foreign audiences, the translation should be clear and correct, and therefore the translator needs to search the information to find the supporting of why he or she should translate in this way.

According to Wang Tao of the Nanjing Museum (Chaotian Palace), the "Yang" was one of the earliest animals domesticated by the Chinese. In oracle bone inscriptions, big seal script and small seal script, the character "Yang" has a pair of inverted "V" shaped horns, which is just like the goat's slightly curved horns. From the point of view of cultural relics, most of the "Yang" shaped cultural relics are based on the goat as the prototype, and it is rare to see hairy sheep on these relics. For example, in the Sanyang Kaitai porcelain vases of the Qing Dynasty collected in the Chaotian Palace Museum, the three "Yang" in the pattern are goats with long beard and curved horns. [6]

b. "Eight-year of Anti-Japanese War" or "Fourteen-year Anti-Japanese War"

For the translation of anti-Japanese films and television works, the first thing to do is to deal with a national-level 
question, that is, as a translator, he or she should have a sense of mission to let the world know the truth of Chinese history. Although, for most people, "Ba Nian of Anti-Japanese War"1 has already become an phrase which people are used to using, and the "July 7th Lugou Bridge Incident", as the symbol of the outbreak of the Anti-Japanese War, has become a historical common sense, as a translator, we should let the world understand the crimes committed by the Japanese Empire to the poor Chinese people 70 years ago, and we should let them recognize the facts and face up to the history. [7] We need to seriously consider a question: how to deal with the number "Ba Nian" in the phrase "Ba Nian of Anti-Japanese War" in the translation of films and television works related to the history of China's anti-Japanese war? We should make it clear that the Anti-Japanese War lasted for 14 years, from the "September 18 Incident" of 1931 to the end of 1945, instead of just 8 years. The "September 18 Incident" was the starting point of the Chinese People's Anti-Japanese War and was the prelude to the World Anti-Fascist War. Facing the severe international and domestic situation, we should study the history of the 14-year Anti-Japanese War in a unified way. [8] Therefore, as translator with a sense of national mission, we should confirmedly translate the Chinese characters "Ba Nian" into "fourteen years" instead of "eight years".

To some extent, film and television works about the Anti-Japanese War is one of the most effective way to let the world be clear about the historical truth, and therefore, on the basis of deepening historical research, guided by historical materialism, translator should make these audiovisual works play their role in external publicity.

\section{Conclusion}

Cultural communication ability is an important symbol of a country's cultural soft power, and it is one of China's major policies to strengthen the communication of Chinese culture to the outside world. As a cultural product, audiovisual work, no matter film or television, is one of the most effective means of publicity. As a special kind of translation, the film and television translation will be influenced by various elements, which forms the overt and covert dimensions of audiovisual works: picture, sound and text, and culture.

As for the translation of the "overt dimension" which comes from sound, picture and text, the translator needs to consider the micro constraints, namely time, space, and the content of text and so on. And about the translation of the "covert dimension" which is generated by the interaction of those overt dimensions, the translator needs to consider macro constraints, namely national tradition, ideology, national policy, etc. Therefore, from the deconstruction of audiovisual work (film and television) and the re-construction of its translation, translators should make clear the overt and covert dimensions of film and television works and avoid the opinion that film and television translation is just the simple conversion of the subtitle text in one language into another language.

\section{References}

Gao, Z. H. (2017). Emphasizing the great practical significance of the "14-year Anti-Japanese War" [J]. People's Forum, 2017(S1), 143-144.

\footnotetext{
1 The Chinese characters "Ba Nian" in the phrase "Ba Nian of Anti-Japanese War" means eight years.
} 
Li, K. 1. (2020). Analysis of International Communication of Chinese Films from the Perspective of Culture Going Abroad [D]. Beijing Foreign Studies University, 2020.

Zhang, W. J. (2020). Historical View of the Fourteen-year Anti-Japanese War and New Discussion on the Exposition Framework of Thirty Years of Modern Chinese Literature. [J]. Literary and Art Controversy, 2020(07), 41-50.

https://encyclopedia.thefreedictionary.com/film

https://baike.baidu.com/item/\%E4\%B8\%AD\%E5\%A4\%AE\%E5\%B9\%BF\%E6\%92\%AD\%E7\%94\%B5\%E8\%A7\%86

$\%$ E6\%80\%BB\%E5\%8F\%B0\%Е6\%98\%A5\%Е8\%8A\%82\%Е8\%81\%94\%Е6\%AC\%A2\%Е6\%99\%9A\%Е4\%BC\% 9A/23286677?fromtitle=\%E6\%98\%A5\%E6\%99\%9A\&fromid=10802389\&fr=aladdin

http://news.sohu.com/20150216/n409050331.shtml

\section{Copyrights}

Copyright for this article is retained by the author(s), with first publication rights granted to the journal.

This is an open-access article distributed under the terms and conditions of the Creative Commons Attribution license (http://creativecommons.org/licenses/by/4.0/). 